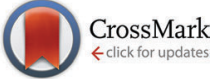

Cite this: Phys. Chem. Chem. Phys., $2016,18,16274$

Received 11th April 2016 , Accepted 19th May 2016

DOI: $10.1039 / \mathrm{c} 6 \mathrm{cp} 02409 \mathrm{~b}$

www.rsc.org/pccp

\title{
New boron based salts for lithium-ion batteries using conjugated ligands
}

\author{
P. Jankowski, ${ }^{* a b c}$ W. Wieczorek ${ }^{a c}$ and P. Johansson ${ }^{b c}$
}

A new anion design concept, based on combining a boron atom as the central atom and conjugated systems as ligands, is presented as a route for finding alternative Li-salts for lithium-ion batteries. The properties of a wide range of novel anions designed in this way have been evaluated by DFT calculations focusing on three different fundamental success factors/measures: the strength of the cation-anion interaction, ultimately determining both the solubility and the ionic conductivity, the oxidation limit, determining their possible use vs. high voltage cathodes, and the reduction stability, revealing a possible role of the anion in the SEl-formation at the anode. For a few anions superior properties vs. today's existing or suggested anions are predicted, especially the very low cation-anion interaction strengths are promising features. The design route itself is shown to be versatile in determining the correlation between different choices of ligands and the resulting overall properties - where the most striking feature is the decreased lithium cation interaction energy upon using the (1Z,3Z)-buta-1,3-diene-1,2,3,4tetracarbonitrile ligands. This also opens avenues for the further design of novel anions beyond those with a boron central atom.

\section{Introduction}

Ever since the commercialization of rechargeable lithium-ion batteries (LIBs), lithium hexafluorophosphate $\left(\mathrm{LiPF}_{6}\right)$ is the most commonly used electrolyte salt, owing to its well-balanced set of properties, ${ }^{1}$ high salt dissociation degree and therefore high ionic conductivity of its carbonate solvent based electrolytes, wide electrochemical stability windows (ESWs) - stability towards oxidation and reduction or meta-stability leading to the formation of a protective layer, and compatibility towards other battery components such as solvents, active materials, and current collectors. However, $\mathrm{LiPF}_{6}$ also has severe safety problems that are difficult to mitigate completely and that are likely contributors to life-length limits of today's LIBs; it is very easily hydrolyzed, eventually resulting in the release of hazardous HF, and has poor thermal stability causing continuous electrolyte degradation. ${ }^{2-6}$ Therefore, new lithium salts are urged for, but any such salt must outperform $\mathrm{LiPF}_{6}$ with respect to many of the above requisite properties to be interesting as a replacement.

Luckily, many of the above requisite basic properties can be successfully estimated by standard computational chemistry

\footnotetext{
${ }^{a}$ Faculty of Chemistry, Warsaw University of Technology, ul. Noakowskiego 3, 00-664 Warsaw, Poland. E-mail: piotr.jankowski@chalmers.se

${ }^{b}$ Department of Physics, Chalmers University of Technology, SE-412 96, Gothenburg, Sweden

${ }^{c}$ ALISTORE-ERI European Research Institute, 33 rue Saint Leu, 80039, Amiens, France
}

methods, enabling us to search for new promising Li-salts/ anions by in silico screening methods and thereby saving time and money by complementing/replacing costly exploratory synthesis. ${ }^{7-10}$ For instance, the salt dissociation degree can be evaluated as the interaction energy between the lithium cation and the anion, the ion-pair dissociation energy, which strongly depends on the charge distribution in the anion. ${ }^{11}$ To achieve the lowest energy of dissociation by the most extensive delocalization of the negative charge within the anion, strongly electron withdrawing groups are applied to the anion structures; e.g. $-\mathrm{F},-\mathrm{CF}_{3},-\mathrm{CN},>\mathrm{CO}$, and $>\mathrm{SO}_{2}{ }^{12}$

Also the ESWs can be evaluated, ${ }^{10,13}$ and while the oxidation potential limit of the anion unquestionably should be as high as possible to accommodate high voltage cathode active materials, there is no similar strict demand for the reduction potential limit. Even the most used solvents, the organic carbonates, undergo reduction processes at potentials of $c a .1 \mathrm{~V} v s$. $\mathrm{Li}^{+} / \mathrm{Li}^{0}$. Therefore, it is essential to provide a kinetic stability against further solvent reduction by forming a stable solid electrolyte interphase (SEI) layer on the anode surface. A salt with the ability to decompose in a controlled manner and create a SEI layer is therefore highly desirable ${ }^{14}$ - exemplified by lithium salts with anions based on boron central atoms such as lithium bis(malonato)borate (LiBMB) and lithium bis(oxalato)borate (LiBOB). ${ }^{15}$ Also the lithium bis(trifluoromethanesulfonylimide) (LiTFSI) salt forms adequate SEI layers, but only at very high concentrations. ${ }^{16}$ Moreover, even the thermal stability can be assessed, including the prediction of decomposition products, 
and has provided clear explanations for the thermal decomposition mechanism of $\mathrm{LiPF}_{6}$-based electrolytes. ${ }^{17}$ Recently, COSMO ${ }^{18}$ approaches have been used for electrolyte studies to predict properties such as viscosities, solubilities and melting points. ${ }^{19}$

Previously, many variations of the imide $\left(\mathrm{N}\left(\mathrm{SO}_{2} \mathrm{C}_{n} \mathrm{~F}_{2 n+1}\right)_{2}{ }^{-}\right),{ }^{12}$ including e.g. the TFSI and the bis(fluorosulfonyl)imide (FSI) anions, and the Hückel $\left(\mathrm{C}_{n} \mathrm{~N}_{5-n}\left(\mathrm{CF}_{3}\right)_{m}(\mathrm{CN})_{n-m}{ }^{-}\right),{ }^{20,21}$ including e.g. the 4,5-dicyano-1,2,3-triazolate (DCTA) and the 4,5-dicyano-2(trifluoromethyl)imidazolide (TDI) anions, families of anions have been in silico screened as $\mathrm{PF}_{6}{ }^{-}$alternatives. So far, some experiments suggest that $\mathrm{LiPF}_{6}$ indeed could be replaced by one of these three main concepts, as represented by, for example, LiTFSI, ${ }^{22}$ LiBOB $^{23}$ or LiTDI. ${ }^{24}$ They all exhibit higher thermal stabilities, are resistant to hydrolysis, and provide sufficient conductivities of their electrolytes. Application of cyano rather than fluorinated ligands, as for TDI, also makes for less environmentally demanding salts - as we avoid fluorine synthesis. Each of these salts, however, has some fundamental drawbacks and common to all is a higher cost of production. Furthermore, LiTFSI does not properly passivate the aluminum current collector, causing its corrosion and degradation during the entire life of a LIB, ${ }^{25}$ while LiBOB shows low solubility in organic carbonate solvents, a critical parameter especially at low operation temperatures. ${ }^{26}$ LiTDI in turn, has problems in creating a stable SEI. ${ }^{27}$

Herein, we apply in silico screening to a new anion design concept, combining two current leading ideas: a tetrahedral boron atom as the anion core ${ }^{28-31}$ and a conjugated system as the anion ligand $;^{24,32}$ here composed of parts of imidazole and pyrrole rings of Hückel anions. All the resulting anions are extensively compared with a wide range of other relevant anions: (i) tetrahedral boron-centered anions: $\mathrm{BF}_{4}{ }^{-}, \mathrm{B}\left(\mathrm{CH}_{3}\right)_{4}{ }^{-}, \mathrm{BPh}_{4}{ }^{-}, \mathrm{BISON}\left[\mathrm{B}(\mathrm{CN})_{4}{ }^{-}\right]$, BPFPB $\left[\left(\mathrm{C}_{2}\left(\mathrm{CF}_{3}\right)_{4} \mathrm{O}_{2}\right)_{2} \mathrm{~B}^{-}\right],{ }^{23}$ BBB $\left[\left(1,2-\mathrm{C}_{6} \mathrm{H}_{4} \mathrm{O}_{2}\right)_{2} \mathrm{~B}^{-}\right],{ }^{33} 4 \mathrm{~F}-\mathrm{BBB}$ $\left[\left(1,2-\mathrm{C}_{6} \mathrm{~F}_{4} \mathrm{O}_{2}\right)_{2} \mathrm{~B}^{-}\right],{ }^{34} \mathrm{BCB}\left[\left(\mathrm{C}_{5} \mathrm{O}_{5}\right)_{2} \mathrm{~B}^{-}\right],{ }^{35}$ BNB $\left[\left(2,3-\mathrm{C}_{10} \mathrm{H}_{6} \mathrm{O}_{2}\right)_{2} \mathrm{~B}^{-}\right],{ }^{34}$ BBPB $\left[\left(2,2^{\prime}-\mathrm{C}_{12} \mathrm{H}_{6} \mathrm{O}_{2}\right)_{2} \mathrm{~B}^{-}\right],{ }^{36}$ BSB $\left[\left(\mathrm{C}_{7} \mathrm{H}_{4} \mathrm{O}_{3}\right)_{2} \mathrm{~B}^{-}\right],{ }^{37} \mathrm{BOB}^{38}$ and $\mathrm{BMB}^{23}$ (ii) conjugated anions: DCTA, ${ }^{39}$ TIM $\left(\mathrm{C}_{6} \mathrm{~N}_{5}^{-}\right),{ }^{40}$ TCP $\left(\mathrm{C}_{8} \mathrm{~N}_{5}{ }^{-}\right),{ }^{40}$ PCPI $\left[\mathrm{C}_{3}(\mathrm{CN})_{5}{ }^{-}\right],{ }^{40}$ TDI, ${ }^{41}$ TDBI $\left(\mathrm{C}_{9} \mathrm{~N}_{4} \mathrm{H}_{2} \mathrm{CF}_{3}{ }^{-}\right)^{42}$ and TDPI $\left(\mathrm{C}_{7} \mathrm{~N}_{6} \mathrm{CF}_{3}{ }^{-}\right)^{43}$ and (iii) standard LIB electrolyte anions: $\mathrm{PF}_{6}{ }^{-}$, $\mathrm{AsF}_{6}{ }^{-}$, and TFSI. All anion data are compared by three different measures: the cation-anion interaction strength, stability $v s$. oxidation, and stability $v s$. reduction.

\section{Computational}

Five ligands with conjugated backbones were applied: (1,2-dicyanoethane-1,2-diylidene)diazanide $\left(\mathrm{C}_{4} \mathrm{~N}_{4}{ }^{2-}\right),(1,1,1,4,4,4-$ hexafluorobutane-2,3-diylidene)diazanide $\left(\mathrm{C}_{4} \mathrm{~F}_{6} \mathrm{~N}_{2}{ }^{2-}\right)$, (1,2-difluoroethane-1,2-diylidene)diazanide $\left(\mathrm{C}_{2} \mathrm{~F}_{2} \mathrm{~N}_{2}{ }^{2-}\right)$, [(Z)-1,2-dicyanoethene1,2-diyl]diazanidecarbonitrile $\left(\mathrm{C}_{6} \mathrm{~N}_{6}{ }^{2-}\right)$, and (1Z,3Z)-buta-1,3-diene1,2,3,4-tetracarbonitrile $\left(\mathrm{C}_{8} \mathrm{~N}_{4}{ }^{2-}\right)$. For each choice of ligand, three boron-centered anions were built by: (i) two ligands of the same type, (ii) one ligand and two cyano groups, and (iii) one ligand and two fluorine atoms, thereby 15 new anions were generated in total (Fig. 1).

The electronic dissociation energy $\left(\Delta E_{\mathrm{d}}\right)$ moving from a $\mathrm{Li}^{+}-$ anion ion-pair to separated ions was calculated for all anions<smiles>N#CC1=N[B-]2(N=C1C#N)N=C(C#N)C(C#N)=N2</smiles>

BDB<smiles></smiles>

BTMB<smiles></smiles>

BFB<smiles>N#CC1=C(C#N)N(C#N)N(C#N)C(C#N)=C1C#N</smiles>

BTCB

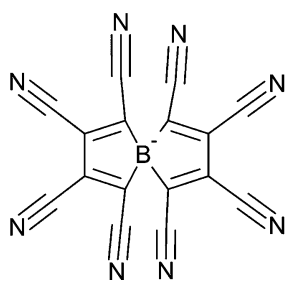

BBTCB

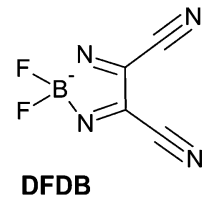

DFTMB<smiles>FC1=N[B-](F)(F)N=C1F</smiles>

DFFB<smiles>N#CC1=C(C#N)N(C#N)B(F)N1C#N</smiles><smiles>N#CC1=C(F)[P-](F)(F)C(C#N)=C1C#N</smiles>

DFBTCB
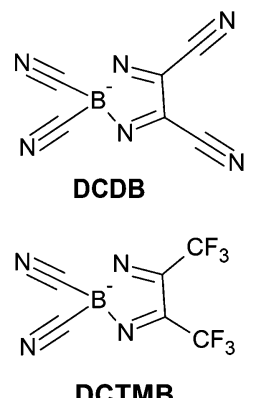

DCTMB
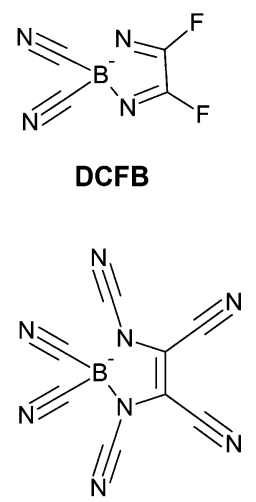

DCTCB

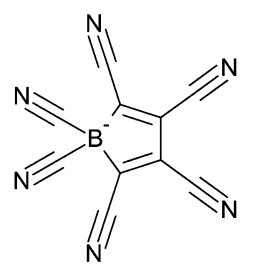

DCBTCB
Fig. 1 The chemical structures of the proposed anions.

using an approach outlined before. ${ }^{44,45}$ Initially the geometry of each anion was optimized and subsequently a lithium cation was manually inserted at a wide range of possible coordination sites including mono-, bi- and tri-dentate coordination, creating up to 15 different ion-pairs for each anion, and the geometries of all the resulting ion-pairs were optimized, all using the B3LYP functional ${ }^{46}$ and the $6-311+\mathrm{G}(\mathrm{d})$ basis set. The basis set superposition error (BSSE) was neglected in the ion-pair calculations as it was previously found to be typically only a few $\mathrm{kJ} \mathrm{mol}^{-1}{ }^{44}$ The obtained electron densities were used for an analysis of the charge distribution using the atoms-in-molecules (AIM) theory. ${ }^{47}$

To assess the oxidative electrochemical stability limit $\left(E_{\text {ox }}\right)$ the vertical ionization potentials (IPs) $\left(\Delta E_{\mathrm{v}}\right.$ 's) were calculated as the differences between the anion and the neutral radical electronic energies, without any geometry relaxation of the radical i.e. change from the anion geometry (the Franck-Condon approximation). For a proper assessment of the reduction limit $\left(E_{\mathrm{red}}\right)$ via the electron affinity (EA) it proved necessary to apply a more accurate approach, where the reduced species was relaxed and 
also the solvent influence was considered by applying the C-PCM SCRF solvation model with all solvent parameters for water, foremost $\varepsilon=78$. Water is chosen as a simple proxy for a large dielectric solvent. Due to the possibility of ion-pairs being reduced rather than the anions, the reduction potentials were also calculated for the most stable contact ion-pairs. All potentials were adjusted towards the $\mathrm{Li}^{+} / \mathrm{Li}^{0}$ reference by $-1.46 \mathrm{~V}{ }^{48}$ For all electrochemical stability limit calculations the M06-2X functional ${ }^{49}$ was used, as it was previously found to provide the best predictive power. ${ }^{50}$ This functional was also used to calculate the chemical hardness $(\eta)$ to evaluate the reactivity of the new species. As defined by Pearson, ${ }^{51}$ the chemical hardness is the average of the vertical IP and the vertical EA: $\eta=($ IP - EA $) / 2$. All computations were made using the Gaussian09 program. ${ }^{52}$

\section{Results and discussion}

\subsection{Cation-anion interactions: strength and nature}

For various anions our computational scheme arguably neglects both any BSSE and the solvent effect influence, in order to enable the best possible comparison to literature data. The main purpose is, however, to create a relative scale/ranking of the anions by creating ion-pairs and this results in a large set of stable structures and in Fig. 2 the obtained $\Delta E_{\mathrm{d}}$ 's for the most stable cation-anion ion-pairs and the $\Delta E_{\mathrm{v}}$ 's for the anions, respectively, are collected in a so-called Scheers-plot. ${ }^{46}$ The various novel ligands applied to create the anions are easily identifiable by the use of different colors. The use of various -CN groups, in red, blue and purple, rather than $-\mathrm{F}$ (green) or $-\mathrm{CF}_{3}$ (yellow) as ligands, clearly promotes a reduction of the cation-anion interaction energy. All $\Delta E_{\mathrm{d}}$ values are collected in Table 1 . The application of fluorinated ligands lowers $\Delta E_{\mathrm{d}}$ values down to $518 \mathrm{~kJ} \mathrm{~mol}^{-1}$ for DCFB and $498 \mathrm{~kJ} \mathrm{~mol}^{-1}$ for DCTMB, while using the same ligand backbone but with $-\mathrm{CN}$ groups,

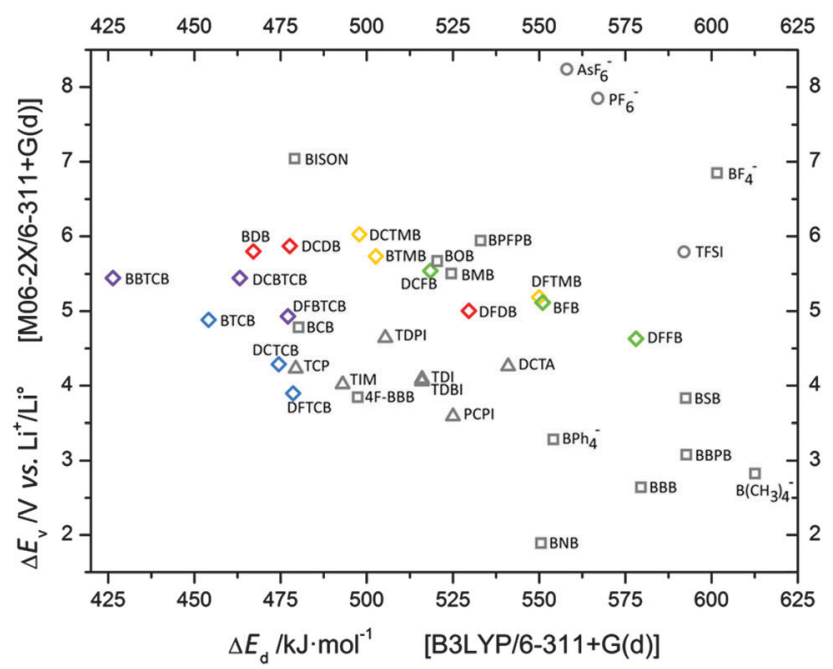

Fig. 2 A Scheers-plot showing the ion-pair dissociation energies $\left(\Delta E_{\mathrm{d}}\right)$ and the anion oxidation potentials $\left(\Delta E_{\mathrm{v}}\right)$ for the novel anions (diamonds) and a few reference systems; boron centered anions - squares, Hückel anions - triangles and standard anions - circles. lowers the $\Delta E_{\mathrm{d}}$ significantly, down to $467 \mathrm{~kJ} \mathrm{~mol}^{-1}$ for BDB. Overall, the conjugated - $\mathrm{CN}$ based ligands create weaker cationanion interactions than the use of conventional -CN groups, and all fluorinated ligands are even weaker. This can clearly be seen by comparing with $\Delta E_{\mathrm{d}}\left(479 \mathrm{~kJ} \mathrm{~mol}^{-1}\right)$ for BISON, containing only conventional $-\mathrm{CN}$ group ligands.

The introduction of further modifications, such as adding -CN groups to nitrogen atoms to form [(Z)-1,2-dicyanoethene1,2-diyl]diazanidecarbonitrile ligands or even a higher substitution degree by replacing these nitrogen atoms by carbon atoms, results in even lower $\Delta E_{\mathrm{d}}$ values: 454 and $426 \mathrm{~kJ} \mathrm{~mol}^{-1}$, respectively, for BTCB and BBTCB. The very low cation-anion interaction strength obtained for the latter anion is in fact lower than for any other LIB electrolyte relevant ion-pair that we know of. The comparable lithium salts from the literature with anions based on a boron central atom, except the said BISON, reaches $\Delta E_{\mathrm{d}}$ 's of $520-525 \mathrm{~kJ} \mathrm{~mol}^{-1}$ for BOB and $\mathrm{BMB}$, thus similar but higher, but for many others $\Delta E_{\mathrm{d}}$ is closer to $600 \mathrm{~kJ} \mathrm{~mol}^{-1}$ such as for $\mathrm{BF}_{4}{ }^{-}$and $\mathrm{B}\left(\mathrm{CH}_{3}\right)_{4}{ }^{-}$. Also the Hückel salts are not able to compete; their $\Delta E_{\mathrm{d}}$ 's range from $479 \mathrm{~kJ} \mathrm{~mol}^{-1}$ for the pyrolates e.g. TCP, via 493-516 kJ mol ${ }^{-1}$ for imidazolates e.g. TIM and TDI, to $541 \mathrm{~kJ} \mathrm{~mol}^{-1}$ for triazolates e.g. DCTA. As for a comparison with the standard $\mathrm{PF}_{6}{ }^{-}$anion and its ion-pair with $\mathrm{Li}^{+}, \Delta E_{\mathrm{d}}$ is $567 \mathrm{~kJ} \mathrm{~mol}^{-1}$.

As the lithium ion is quite small, thus rendering steric hindrance less likely, the nature of the significant decrease in the interaction energy can primarily be addressed by the anion charge distribution. One crucial parameter, the ligand electron withdrawing force, here measured by the resulting partial charge on the central boron atom, reveals the connecting atom to be the more important design feature, the effect largely stops after the first atom. All the resulting charge distributions for the novel anions are listed in Table 2. A fluorine ligand, a very strong electron withdrawing moiety, can cause an increase in the boron atom charge from +1.57 for $\mathrm{BH}_{4}{ }^{-}$to +2.36 for $\mathrm{BF}_{4}{ }^{-}$, while the oxygen connecting ligands result in $c a .+2.30$, as seen for $\mathrm{BOB}$ and $\mathrm{BMB}$, and more medium effects are observed for carbon connecting ligands such as for $\mathrm{B}\left(\mathrm{CH}_{3}\right)_{4}{ }^{-}$resulting in a boron atom charge of +1.83 . However, there are large differences between normal carbon connecting ligands such as $-\mathrm{CH}_{3}$ and $-\mathrm{Ph}(c a .+1.8)$ and $-\mathrm{CN}$ ligands $(c a .+2.0)$, probably due to the very strong carbon-nitrogen triple-bond.

The novel anions with a ligand coordination of the boron atom by four nitrogen atoms, as for BDB, BTMB, and BFB, provide an average electron withdrawing force resulting in a boron atom charge of $c a .+2.12$ (Table 2). This level appears to be the most appropriate, ensuring a fair charge distribution between the core and the ligands, balancing the need for proper delocalization and the risk of creating negatively charged parts/fragments attractive for lithium ion interaction. The change to BTCB by adding - $\mathrm{CN}$ groups connected to nitrogen atoms only slightly increases the observed effect $(+2.18)$. Further replacement of these nitrogen atoms by carbon atoms, as for BBTCB, results in a decrease to a typical value for carbon connected ligands, +1.84 .

As stated above, the part of the ligand not connecting the central boron atom seems to have no significant direct influence on the core charge. Thus we as a first approximation consider 
Table 1 The ion-pair dissociation energies, anion oxidation potentials, anion chemical hardness and reduction potentials for anions and ion-pairs of the novel anions/lithium salts and references

\begin{tabular}{|c|c|c|c|c|c|}
\hline Anion & $\begin{array}{l}\Delta E_{\mathrm{d}}\left[\mathrm{kJ} \mathrm{mol}^{-1}\right] \\
\text { B3LYP }\end{array}$ & $\begin{array}{l}\Delta E_{\mathrm{v}}\left[\mathrm{V} v s . \mathrm{Li}^{+} / \mathrm{Li}^{0}\right] \\
\mathrm{M} 06-2 \mathrm{X}\end{array}$ & $\begin{array}{l}\eta[\mathrm{eV}] \\
\text { M06-2X }\end{array}$ & $\begin{array}{l}E_{\text {red anion }}\left[\mathrm{V} v s . \mathrm{Li}^{+} / \mathrm{Li}^{0}\right] \\
\text { M06-2X }\end{array}$ & $\begin{array}{l}E_{\text {red ion-pair }}\left[\mathrm{V} v s . \mathrm{Li}^{+} / \mathrm{Li}^{0}\right] \\
\text { M06-2X }\end{array}$ \\
\hline BDB & 467 & 5.80 & 4.48 & 2.00 & 1.84 \\
\hline BTMB & 503 & 5.73 & 4.97 & 1.44 & 1.99 \\
\hline DFTMB & 550 & 5.19 & 5.11 & 1.40 & 1.72 \\
\hline DCTMB & 498 & 6.03 & 5.09 & 1.59 & 1.98 \\
\hline DCFB & 518 & 5.54 & 5.48 & 0.83 & 0.87 \\
\hline ВTCB & 454 & 4.88 & 3.66 & 1.56 & 1.67 \\
\hline DFTCB & 479 & 3.90 & 3.76 & 1.63 & 1.75 \\
\hline DCTCB & 474 & 4.29 & 3.66 & 1.87 & 1.92 \\
\hline BBTCB & 426 & 5.44 & 3.75 & 2.67 & 2.82 \\
\hline DFBTCB & 477 & 4.93 & 3.79 & 2.48 & 2.62 \\
\hline DCBTCB & 463 & 5.44 & 3.75 & 2.62 & 2.79 \\
\hline BISON & 479 & 7.04 & 6.29 & -0.13 & 0.23 \\
\hline BPFPB & 533 & 5.94 & 5.48 & - & - \\
\hline BBB & 580 & 2.64 & 3.81 & -0.64 & -0.46 \\
\hline $4 \mathrm{~F}-\mathrm{BBB}$ & 497 & 3.84 & 4.84 & -0.57 & 0.51 \\
\hline $\mathrm{BCB}$ & 480 & 4.78 & 3.80 & 1.74 & 2.35 \\
\hline BNB & 551 & 1.89 & 3.97 & 0.05 & 0.27 \\
\hline BBPB & 593 & 3.08 & 3.95 & -0.29 & 0.03 \\
\hline BSB & 593 & 3.83 & 4.26 & 0.13 & 0.73 \\
\hline BOB & 520 & 5.67 & 5.37 & 1.28 & 1.72 \\
\hline BMB & 525 & 5.51 & 5.35 & -0.74 & 0.50 \\
\hline DCTA & 541 & 4.26 & 4.99 & 0.34 & 0.51 \\
\hline TIM & 493 & 4.02 & 4.65 & 0.41 & 0.44 \\
\hline TCP & 479 & 4.23 & 4.33 & 0.81 & 0.97 \\
\hline
\end{tabular}

the core and ligand charge distributions independently. As the observed cation-anion interaction energies result from delocalization of the negative charge, comparing BFB, BTMB and $\mathrm{BDB}$, the $-\mathrm{F}$ ligand at $\mathrm{BFB}$ has the strongest electron withdrawing force with a ligand charge of -0.63 , and will thus possibly strongly interact with the lithium cation via this fluorine ligand. In turn, the $-\mathrm{CF}_{3}$ group of BTMB has a much weaker effect, with the charge of the trifluoromethyl ligand being equal to -0.21 . However, inside the latter ligand there is a significant gradient of charge density: a highly positive carbon atom $(+1.61)$ is surrounded by three strongly electron withdrawing fluorine atoms $(-0.61)$. Thus also the $-\mathrm{CF}_{3}$ ligand can be expected to coordinate strongly to a lithium cation, especially if being able to use two adjacent fluorine atoms in a bi-dentate manner. In contrast, the partial charges of the $-\mathrm{CN}$ groups in $\mathrm{BDB}$ are -0.26 and this provides the lowest $\Delta E_{\mathrm{d}}$, while the large charge density gradients, +0.91 at $\mathrm{C}$ and -1.17 at $\mathrm{N}$, seem to be of less importance and at the same time the lithium cation coordination is mono-dentate.

\subsection{Stability against oxidation}

The stability $v s$. oxidation is a most important property of anions and boron based anions like $\mathrm{BF}_{4}{ }^{-}$and BISON are able to reach 6.85-7.04 V vs. $\mathrm{Li}^{+} / \mathrm{Li}^{0}$ (Fig. 2 and Table 1). However, application of organic ligands, instead of inorganic $-\mathrm{F}$ and $-\mathrm{CN}$, causes a drop in the oxidation stability; the best out of these, the BPFPB anion, reaches merely $5.94 \mathrm{~V} v s . \mathrm{Li}^{+} / \mathrm{Li}^{0}$. Notably the introduction of cyano groups in general increases the stability of the anion. ${ }^{12}$ Here we find that upon connecting the $-\mathrm{CN}$ moiety directly to the boron core, 6.03 and $5.54 \mathrm{Vvs.} \mathrm{Li}^{+} / \mathrm{Li}^{0}$ for DCTMB and DCFB, respectively, as well as to the backbone, 5.80 and $5.00 \mathrm{~V} v s . \mathrm{Li}^{+} / \mathrm{Li}^{0}$ for BDB and DFDB, respectively, the increase in oxidation potential is observed. Only the addition of additional - $\mathrm{CN}$ groups to the nitrogen atom causes a decrease in $\Delta E_{\mathrm{v}}: 4.88 \mathrm{~V} v s . \mathrm{Li}^{+} / \mathrm{Li}^{0}$ for BTCB. The opposite effect was observed for the substitution by fluorine atoms, where $\Delta E_{\mathrm{v}}$ drops to $5.12 \mathrm{~V}$ vs. $\mathrm{Li}^{+} / \mathrm{Li}^{0}$ for $\mathrm{BFB}$ and to $4.63 \mathrm{~V}$ vs. $\mathrm{Li}^{+} / \mathrm{Li}^{0}$ for DFFB, respectively. 
Table 2 The charge distributions for the cores and the ligands of the novel anions

\begin{tabular}{|c|c|c|c|c|c|c|c|}
\hline \multirow[b]{3}{*}{ Anion } & \multirow{3}{*}{$\begin{array}{l}\text { Core } \\
\text { B }\end{array}$} & \multicolumn{6}{|c|}{ Ligands } \\
\hline & & \multirow[b]{2}{*}{$-\mathrm{CN}$} & \multirow[b]{2}{*}{$-F$} & \multicolumn{4}{|c|}{ Conjugated } \\
\hline & & & & Backbone & $-\mathrm{CN}$ & $-F$ & $-\mathrm{CF}_{3}$ \\
\hline BDB & +2.12 & - & - & -1.03 & -0.26 & - & - \\
\hline DFDB & +2.25 & - & -0.82 & -1.02 & -0.29 & - & - \\
\hline DCDB & +2.06 & -0.75 & - & -1.03 & -0.26 & - & - \\
\hline BTMB & +2.12 & - & - & -1.15 & - & - & -0.21 \\
\hline DFTMB & +2.25 & - & -0.82 & -1.14 & - & - & -0.23 \\
\hline DCTMB & +2.06 & -0.76 & - & -1.16 & - & - & -0.20 \\
\hline BFB & +2.13 & - & - & -0.31 & - & -0.63 & - \\
\hline DFFB & +2.25 & - & -0.83 & -0.32 & - & -0.63 & - \\
\hline DCFB & +2.07 & -0.77 & - & -0.27 & - & -0.63 & - \\
\hline BTCB & +2.18 & - & - & -1.77 & $\begin{array}{c}+0.28^{a} \\
-0.19^{b}\end{array}$ & - & - \\
\hline DFTCB & +2.29 & - & -0.82 & -1.67 & $\begin{array}{c}+0.25^{a} \\
-0.23^{b}\end{array}$ & - & - \\
\hline DCTCB & +2.10 & -0.76 & - & -1.70 & $\begin{array}{c}+0.27^{a} \\
-0.21^{b}\end{array}$ & - & - \\
\hline BBTCB & +1.84 & - & - & -0.46 & $\begin{array}{l}-0.25^{a} \\
-0.22^{b}\end{array}$ & - & - \\
\hline DFBTCB & +2.14 & - & -0.81 & -0.40 & $\begin{array}{l}-0.29^{a} \\
-0.27^{b}\end{array}$ & - & - \\
\hline DCBTCB & +1.92 & -0.76 & - & -0.42 & $\begin{array}{l}-0.25^{a} \\
-0.24^{b}\end{array}$ & - & - \\
\hline
\end{tabular}

${ }^{a}$ Nitrile groups close to the boron atom. ${ }^{b}$ Nitrile groups far from the boron atom.

The exchange of an aromatic system for a corresponding conjugated backbone connected to the tetrahedral boron atom seems to be advantageous for oxidation resistance. Application of the imidazole-derived ligand from the anions TDI and TIM, anions which exhibit $\Delta E_{\mathrm{v}}$ 's of $4.05-4.09 \mathrm{~V} v s . \mathrm{Li}^{+} / \mathrm{Li}^{0}$, to the boron-centered anions causes an increased stability; $5.80 \mathrm{~V} v s$. $\mathrm{Li}^{+} / \mathrm{Li}^{0}$ for the BDB anion. Likewise, changing from a typical Hückel anion to a boron-centered anion using a pyrrole ring derived ligand results in an enhancement of $\Delta E_{\mathrm{v}}: 4.23 v s .5 .44 \mathrm{~V}$ vs. $\mathrm{Li}^{+} / \mathrm{Li}^{0}$, for TCP and BBTCB, respectively. Lithium salts with such high oxidation stabilities are very desirable as they allow for application of cathode materials with higher voltages, and thus improved energy density of the battery. However it should be noted that experimental values of the oxidation potential limit $\left(E_{\text {Ox }}\right)$ for Hückel anions (TCP, TIM) are usually higher than predicted with the $\Delta E_{\mathrm{v}}$ approach, above $5 \mathrm{~V} v s . \mathrm{Li}^{+} / \mathrm{Li}^{0}{ }^{54}$ On the other hand, $\Delta E_{\mathrm{v}}$ 's of boron centered anions (BOB, MOB, $\left.\mathrm{B}\left(\mathrm{CH}_{3}\right)_{4}{ }^{-}\right)^{38,55,56}$ overestimate $E_{\mathrm{ox}}$ 's, which are usually ca. $1 \mathrm{~V}$ lower. ${ }^{50}$ Despite these difficulties in correlation, the calculated $\Delta E_{\mathrm{v}}$ 's for anions like BDB, DCDB, BTMB and DCTMB are high enough; 5.73-6.03 $\mathrm{V}$ vs. $\mathrm{Li}^{+} / \mathrm{Li}^{0}$, to consider their application to the cathode material $\mathrm{LiNi}_{0.5} \mathrm{Mn}_{1.5} \mathrm{O}_{4}$, requiring stability up to $4.7 \mathrm{~V} v s$. $\mathrm{Li}^{+} / \mathrm{Li}^{0}{ }^{53}$ On the other hand, also the salts with the lowest stabilities vs. oxidation, DFTCB and DCTCB with $\Delta E_{\mathrm{v}}$ 's of $3.90-4.29 \mathrm{~V} v s . \mathrm{Li}^{+} / \mathrm{Li}^{0}$, might still be able to work with standard cathode materials such as $\mathrm{LiFePO}_{4}$ with a mere need for stability up to $3.45 \mathrm{~V} v s$. $\mathrm{Li}^{+} / \mathrm{Li}^{0}{ }^{57}$

\subsection{Stability against reduction}

Another significant property is the stability $v s$. reduction, as it is important for all battery electrolyte components to be either stable or enabling the creation of a passivation layer. In particular, decomposition of a salt anion above $1 \mathrm{~V} v s . \mathrm{Li}^{+} / \mathrm{Li}^{0}$ can be used to protect the electrolyte carbonate solvents such as EC, PC and DMC against decomposition. The latter is quite typical for boron-based salts, the best example is LiBOB $\left(E_{\text {red }}=\right.$ $\left.1.28 \mathrm{~V} v s . \mathrm{Li}^{+} / \mathrm{Li}^{0}\right)$ that creates SEIs with very good properties. ${ }^{58}$ However, even a slight modification of BOB into the BMB anion causes a significant drop in $E_{\text {red }}$ to $-0.74 \mathrm{Vvs.} \mathrm{Li}^{+} / \mathrm{Li}^{0}$, rendering the latter much less useful for carbonate solvent decomposition protection. In Fig. 3 the $E_{\text {red }}$ values of both the novel anions and their ion-pairs are presented. In most cases the presence of a lithium cation indeed facilitates the process of electron acceptance, the only exception is the BDB anion where the $\mathrm{Li}^{+}$ coordination slightly stabilizes the structure. There are also a few anions where the anion and the ion-pairs have approximately equal $E_{\text {red }}$ DCFB and DCTCB. In general, however, the differences in $E_{\text {red }}$ between the ion-pairs and the anions are of the order $0.1-0.6 \mathrm{~V}$.

The most stable anions/ion-pairs, i.e. the lowest reduction potentials were obtained for anions containing the (1,2-difluoroethane-1,2-diylidene)diazanide ligand, such as BFB, DFFB and DCFB, 1.01, 0.98 and $0.87 \mathrm{~V}$ vs. $\mathrm{Li}^{+} / \mathrm{Li}^{0}$ for their ion-pairs. Changing to conjugated ligands with $-\mathrm{CN}$ groups results in larger increases in the reduction ability, 1.84, 2.17, and $2.36 \mathrm{~V}$ vs. $\mathrm{Li}^{+} / \mathrm{Li}^{0}$ for the ion-pairs of BDB, BFBD and DCBD, respectively. Application of another - $\mathrm{CN}$ group to nitrogen atoms causes a little drop in $E_{\text {red }} ; 1.67 v s . \mathrm{Li}^{+} / \mathrm{Li}^{0}$ for BTCB. The least stable anions are those containing the pyrrole-derived ligand - for

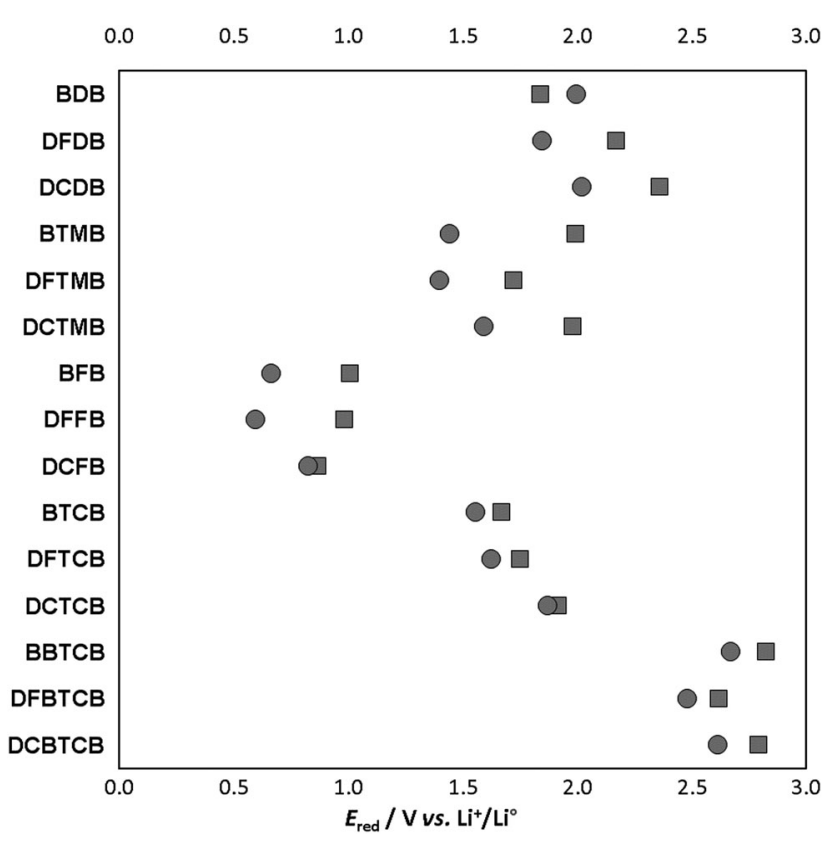

Fig. 3 Reduction potentials for anions (circles) and ion-pairs (squares) of the novel lithium salts. 
BBTCB, DFTCB and DCBTCB, the reduction potentials all exceed $2.5 \mathrm{~V} v s . \mathrm{Li}^{+} / \mathrm{Li}^{0}$, seemingly preventing any use in LIBs.

\subsection{Chemical hardness}

An additional parameter that can be explored with relevance to the requisite properties is the chemical hardness $(\eta)$, i.e. the resistance of an ion or a molecule to change its charge. It can be used both to explain the level of interaction by donation/ acceptance of very small amounts of charge, similar to the HSAB concept,${ }^{59}$ as well as a good approximation of the ability to donate/accept an electron to/from the electrode. The latter means that for anions that are thought to serve to create an SEI by reduction at the anode, the chemical hardness also serves as a kinetic measure as it is a descriptor of reaction resistance. ${ }^{60}$

For the series of halide anions $\mathrm{F}^{-}, \mathrm{Cl}^{-}$and $\mathrm{Br}^{-}$their $\eta$ values of 6.02, 4.89 and $4.37 \mathrm{eV}^{50}$ correlate well with both their $\Delta E_{\mathrm{d}}$ 's of 778,645 and $612 \mathrm{~kJ} \mathrm{~mol}^{-1},{ }^{45}$ and their $\Delta E_{\mathrm{v}}$ 's of $1.71,2.23$ and $2.03 \mathrm{~V} v s . \mathrm{Li}^{+} / \mathrm{Li}^{0}{ }^{50}$ Our results show that the chemical hardness is in very good agreement with the degree of charge delocalization within the anion (Table 1). The application of fluorine atoms, both as the boron center and as part of the conjugated ligand, results in higher $\eta$ values; 4.58, 5.34 and $5.50 \mathrm{eV}$ for DFDB, BFB and DFFB, respectively, a little lower value is observed for ligands with the $-\mathrm{CF}_{3}$ group; 4.97 and $5.11 \mathrm{eV}$ for BTMB and DDFTMB. The use of -CN ligands results in lower chemical hardness: down to $4.48 \mathrm{eV}$ for $\mathrm{BDB}$, but the application of up to four - $\mathrm{CN}$ groups per ligand results in very low chemical hardness, below $4 \mathrm{eV}$ as shown for BTCB and BBTCB, $3.66 \mathrm{eV}$ and $3.75 \mathrm{eV}$, respectively. The very low cation-anion interaction energies for the BBTCB and BTCB anions can be explained by this and in general such low levels of chemical hardness are rarely observed, even for completely conjugated and aromatic Hückel anions, only the PCPI pseudo-aromatic anion reaches as low as $3.59 \mathrm{eV}$. The common LIB anions, such as $\mathrm{PF}_{6}{ }^{-}$ and TFSI, are above 7 and $5 \mathrm{eV}$, respectively.

\section{Conclusions}

In this paper we present an idea of novel anions by combining conjugated ligands and boron centres, to benefit from the advantages of both. They all have extensive delocalization of the negative charge and thereby achieve anions with very small lithium-ion interaction energies, even below $430 \mathrm{~kJ} \mathrm{~mol}^{-1}$, which is $c a .75 \%$ of $\mathrm{Li}^{+}-\mathrm{PF}_{6}{ }^{-}$. Moreover, compared to other similar salts e.g. aromatic Hückel anions, the tetrahedral boron centred salts with conjugated ligands should have improved oxidation stabilities, enabling application in high voltage cathodes - even at $5 \mathrm{~V}$ vs. $\mathrm{Li}^{+} / \mathrm{Li}^{0}$. The here suggested anions BDB, DCDB and possibly BBTCB could all provide excellent, easily dissociative salts for high voltage LIB cells. Another very promising anion - BTCB - could be applied in standard LIBs at lower voltages. Most of the new anions are not only able to provide charge carriers for high conductivity of their electrolytes, but also help to stabilize the SEI between the anode and the electrolyte by virtue of their tailored reduction voltages, and those who do not, for example DCFB, BFB and DFFB, could possibly rather be applied to anodes such as LTO $^{61}$ than the standard graphite. Other important parameters for future battery application, such as solubility and aluminum corrosion protection, were not targeted, but nevertheless, even if failing in any of these aspects, the salts can be proposed as SEI forming additives.

\section{Acknowledgements}

The authors acknowledge Prof. Michael Armand, CIC Energigune, and the ALISTORE-ERI community for many valuable discussions. All calculations have been carried out at the Wroclaw Centre for Networking and Supercomputing (http://www.wcss.pl), grant no. 346. The support by ALISTORE-ERI for doctoral studies and by Chalmers Area of Advance Energy for travel scholarships to Piotr Jankowski are both gratefully acknowledged. Patrik Johansson acknowledges both the Swedish Energy Agency for a basic research grant via the Swedish Research Council and the continuous support by many of Chalmers Areas of Advance: Energy, Materials Science, and Transport.

\section{References}

1 J. T. Dudley, D. P. Wilkinson, G. Thomas, R. LeVae, S. Woo, H. Blom, C. Horvath, M. W. Juzkow, B. Denis, P. Juric, P. Aghakian and J. R. Dahn, J. Power Sources, 1991, 35, 59-82.

2 A. V. Plakhotnyk, L. Ernst and R. Schmutzler, J. Fluorine Chem., 2005, 126, 27-31.

3 C. L. Campion, W. Li and B. L. Lucht, J. Electrochem. Soc., 2005, 152, A2327-A2334.

4 G. Gachot, P. Ribère, D. Mathiron, S. Grugeon, M. Armand, J.-B. Leriche, S. Pilard and S. Laruelle, Anal. Chem., 2011, 83, 478-485.

5 S. Wilken, P. Johansson and P. Jacobsson, Solid State Ionics, 2012, 225, 608-610.

6 S. Wilken, M. Treskow, J. Scheers, P. Johansson and P. Jacobsson, RSC Adv., 2013, 3, 16359-16364.

7 L. Cheng, R. S. Assary, X. Qu, A. Jain, S. P. Ong, N. N. Rajput, K. Persson and L. A. Curtiss, J. Phys. Chem. Lett., 2015, 6, 283-291.

8 J. Knap, C. E. Spear, O. Borodin and K. W. Leiter, Nanotechnology, 2015, 26, 434004.

9 R. S. Assary, L. A. Curtiss, P. C. Redfern, Z. Zhang and K. Amine, J. Phys. Chem. C, 2011, 115, 12216-12223.

10 M. Korth, Phys. Chem. Chem. Phys., 2014, 16, 7919-7926. 11 P. Johansson, Phys. Chem. Chem. Phys., 2007, 9, 1493-1498. 12 J. Scheers, E. Jonsson, P. Jacobsson and P. Johansson, Electrochemistry, 2012, 80, 18-25.

13 P. Johansson, J. Phys. Chem. A, 2006, 110, 12077-12080.

14 T. Husch and M. Korth, Phys. Chem. Chem. Phys., 2015, 17, 22799-22808.

15 C. Liao, K. S. Han, L. Baggetto, D. A. Hillesheim, R. Custelcean, E.-S. Lee, B. Gue, Z. Bi, D. Jiang, G. M. Veith, E. W. Hagaman, G. M. Brown, C. Bridges, M. P. Paranthaman, A. Manthiram, S. Dai and X.-G. Sun, Adv. Energy Mater., 2014, 4, 1301368. 
16 L. Suo, O. Borodin, T. Gao, M. Olguin, J. Ho, X. Fan, C. Luo, C. Wang and K. Xu, Science, 2015, 350, 938-943.

17 Y. Okamoto, J. Electrochem. Soc., 2016, 160, A404-A409.

18 A. Klamt, WIREs Comput. Mol. Sci., 2011, 1, 699-709.

19 T. Husch, N. D. Yilmazer, A. Balducci and M. Korth, Phys. Chem. Chem. Phys., 2015, 17, 3394-3401.

20 P. Johansson, H. Nilsson, P. Jacobsson and M. Armand, Phys. Chem. Chem. Phys., 2004, 6, 895-899.

21 E.G. Leggesse, J.-C. Jiang, ECS Meeting Abstracts, 2015, MA2015-01, 412.

22 L. A. Dominey, V. R. Koch and T. Blakley, Electrochim. Acta, 1992, 37, 1551-1554.

23 W. Xu, A. Shusterman, M. Videa, V. Velikov, R. L. Marzke and C. A. Angell, J. Electrochem. Soc., 2003, 150, E74-E80.

24 L. Niedzicki, S. Grugeon, S. Laruelle, P. Judeinstein, M. Bukowska, J. Prejzner, P. Szczecinski, W. Wieczorek and M. Armand, J. Power Sources, 2011, 196, 8696-8700.

25 L. J. Krause, W. Lamanna, J. Summerfield, M. Engle, G. Korba, R. Loch and R. Atanasoski, J. Power Sources, 1997, 68, 320-325.

26 K. Xu, S. S. Zhang, U. Lee, J. L. Allen and T. R. Jow, J. Power Sources, 2005, 146, 79-85.

27 S. Paillet, G. Schmidt, S. Ladouceur, J. Frechette, F. Barray, D. Clement, P. Hovington, A. Guerfi, A. Vijh, I. Cayrefourcq and K. Zaghib, J. Power Sources, 2015, 299, 309-314.

28 J. Huang, L.-Z. Fan, B. Yu, T. Xing and W. Quin, Ionics, 2010, 16, 509-513.

29 M. Amereller, T. Schedlbauer, D. Moosbauer, C. Schreiner, C. Stock, F. Wudy, S. Zugmann, H. Hammer, A. Maurer, R. M. Gschwind, H. D. Wimhofer, M. Winter and H. J. Gores, Prog. Solid State Chem., 2014, 42, 39-56.

30 W. Xu and C. A. Angell, Electrochem. Solid-State Lett., 2000, 3, 366-368.

31 M. Handa, S. Fukuda, Y. Sasaki and K. Usami, J. Electrochem. Soc., 1997, 144, L235-L237.

32 T. J. Barbarich and P. F. Driscoll, Electrochem. Solid-State Lett., 2003, 6, A113-A116.

33 J. Barthel, M. Wuhr, R. Buestrich and H. J. Gores, J. Electrochem. Soc., 1995, 142, 2527-2531.

34 J. Barthel, R. Buestrich, E. Carl and H. J. Gores, J. Electrochem. Soc., 1996, 143, 3572-3575.

35 Z.-M. Xue, Y.-Z. Ding and C.-H. Chen, Electrochim. Acta, 2007, 53, 990-997.

36 J. Barthel, R. Buestrich, H. J. Gores, M. Schmidt and M. Wu, J. Electrochem. Soc., 1997, 144, 3866-3870.

37 D. Aurbach, J. S. Gnanaraj, W. Geissler and M. Schmidt, J. Electrochem. Soc., 2004, 151, A23-A30.

38 W. Xu and C. A. Angell, Electrochem. Solid-State Lett., 2001, 4, E1-E4.

39 M. Egashira, B. Scrosati, M. Armand, S. Beranger and C. Michot, Electrochem. Solid-State Lett., 2003, 6, A71-A73.

40 A. Bitner, G. M. Nolis, T. Trzeciak, G. Z. Żukowska, L. Niedzicki, W. Wieczorek and M. Marcinek, ECS Meeting Abstracts, 2015, MA2015-01, 411.

41 L. Niedzicki, M. Kasprzyk, K. Kuziak, G. Z. Żukowska, M. Armand, M. Bukowska, M. Marcinek, P. Szczeciński and W. Wieczorek, J. Power Sources, 2009, 192, 612-617.
42 L. Niedzicki, J. Korczak, A. Bitner, M. Bukowska and P. Szczeciński, RSC Adv., 2015, 5, 101917.

43 L. Niedzicki, P. Oledzki, A. Bitner, M. Bukowska and P. Szczeciński, J. Power Sources, 2016, 306, 573-577.

44 J. Scheers, P. Johansson, P. Szczeciński, W. Wieczorek, M. Armand and P. Jacobsson, J. Power Sources, 2010, 195, 6081-6087.

45 E. Jonsson and P. Johansson, Phys. Chem. Chem. Phys., 2012, 14, 10774-10779.

46 A. D. Becke, J. Chem. Phys., 1993, 98, 5648-5652.

47 R. F. W. Bader, Atoms in Molecules: A Quantum Theory, Oxford University Press, New York, 1990.

48 S. Trasatti, Pure Appl. Chem., 1986, 58, 955-966.

49 Y. Zhao and D. G. Truhlar, Theor. Chem. Acc., 2008, 120, 215-241.

50 E. Jonsson and P. Johansson, Phys. Chem. Chem. Phys., 2015, 17, 3697-3703.

51 R. G. Pearson, Inorg. Chem., 1988, 27, 734-740.

52 M. J. Frisch, G. W. Trucks, H. B. Schlegel, G. E. Scuseria, M. A. Robb, J. R. Cheeseman, G. Scalmani, V. Barone, B. Mennucci, G. A. Petersson, H. Nakatsuji, M. Caricato, X. Li, H. P. Hratchian, A. F. Izmaylov, J. Bloino, G. Zheng, J. L. Sonnenberg, M. Hada, M. Ehara, K. Toyota, R. Fukuda, J. Hasegawa, M. Ishida, T. Nakajima, Y. Honda, O. Kitao, H. Nakai, T. Vreven, J. A. Montgomery Jr, J. E. Peralta, F. Ogliaro, M. Bearpark, J. J. Heyd, E. Brothers, K. N. Kudin, V. N. Staroverov, R. Kobayashi, J. Normand, K. Raghavachari, A. Rendell, J. C. Burant, S. S. Iyengar, J. Tomasi, M. Cossi, N. Rega, J. M. Millam, M. Klene, J. E. Knox, J. B. Cross, V. Bakken, C. Adamo, J. Jaramillo, R. Gomperts, R. E. Stratmann, O. Yazyev, A. J. Austin, R. Cammi, C. Pomelli, J. W. Ochterski, R. L. Martin, K. Morokuma, V. G. Zakrzewski, G. A. Voth, P. Salvador, J. J. Dannenberg, S. Dapprich, A. D. Daniels, Ö. Farkas, J. B. Foresman, J. V. Ortiz, J. Cioslowski, D. J. Fox, Gaussian 09, Revision D.01, Gaussian, Inc., Wallingford CT, 2009.

53 R. Santhanam and B. Rambabu, J. Power Sources, 2016, 195, 5442-5451.

54 A. Bitner-Michalska, G. M. Nolis, G. Żukowska, A. Zalewska, M. Poterała, T. Trzeciak, M. Dranka, M. Kalita, P. Jankowski, L. Niedzicki, J. Zachara, W. Wieczorek and M. Marcinek, Chem. Mater., submitted.

55 W. Xu, A. J. Shusterman, R. Marzke and C. A. Angell, J. Electrochem. Soc., 2004, 151, A632-A638.

56 M. Ue, M. Takeda, M. Takehara and S. Mori, J. Electrochem. Soc., 1997, 133, 2684-2688.

57 F. Croce, A. D. Epifanio, J. Hassoun, A. Deptula, T. Olczac and B. Scrosati, Electrochem. Solid-State Lett., 2002, 5, A47-A50.

58 Y. An, P. Zuo, X. Cheng, L. Liao and G. Yin, Electrochim. Acta, 2011, 56, 4841-4848.

59 R. G. Pearson, J. Chem. Educ., 1968, 45, 581-586.

60 M. D. Halls and K. Tasaki, J. Power Sources, 2010, 195, 1472-1478.

61 M. M. Thackeray, J. Electrochem. Soc., 1994, 141, L147-L150. 